\title{
Developing an ionospheric map for South Africa
}

\author{
D. I. Okoh ${ }^{1,2}$, L. A. McKinnell ${ }^{1,2}$, and P. J. Cilliers ${ }^{1}$ \\ ${ }^{1}$ Hermanus Magnetic Observatory, P.O. Box 32, Hermanus, South Africa \\ ${ }^{2}$ Department of Physics and Electronics, Rhodes University, P.O. Box 24, Grahamstown, South Africa
}

Received: 12 August 2009 - Revised: 19 June 2010 - Accepted: 5 July 2010 - Published: 12 July 2010

\begin{abstract}
The development of a map of the ionosphere over South Africa is presented in this paper. The International Reference Ionosphere (IRI) model, South African Bottomside Ionospheric Model (SABIM), and measurements from ionosondes in the South African Ionosonde Network, were combined within their own limitations to develop an accurate representation of the South African ionosphere. The map is essentially in the form of a computer program that shows spatial and temporal representations of the South African ionosphere for a given set of geophysical parameters. A validation of the map is attempted using a comparison of Total Electron Content (TEC) values derived from the map, from the IRI model, and from Global Positioning System (GPS) measurements. It is foreseen that the final South African ionospheric map will be implemented as a Space Weather product of the African Space Weather Regional Warning Centre.
\end{abstract}

Keywords. Ionosphere (Mid-latitude ionosphere; Modeling and forecasting) - Radio science (Ionospheric propagation)

\section{Introduction}

The ionosphere (that region of our atmosphere extending from an altitude of about $50 \mathrm{~km}$ to about $1000 \mathrm{~km}$ ) affects lives in diverse ways, ranging from its usefulness in High Frequency (HF) radio propagation, to its attenuation of radio signals that have to pass through it. By increasing general ionospheric knowledge above lesser known areas, use of the ionosphere can be greatly enhanced, and significant allowance can be made for the effects ionospheric behaviour can have on radio signals. What distinguishes the ionospheric region from other regions of the atmosphere is that

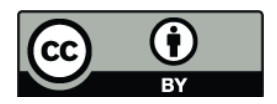

Correspondence to: D. I. Okoh (okodan2003@gmail.com) it contains a reasonable distribution of free electrons. This paper presents the development of a suitable method for describing the behaviour of the ionosphere given the current available sources.

Plasma electrons in the ionosphere are known to oscillate with a characteristic frequency known as the plasma frequency. Chen (1984) showed that the plasma frequency (in units of radians per second) at any point in plasma is given by

$\omega_{p}=2 \pi f=\sqrt{\frac{n e^{2}}{\varepsilon_{0} m}}$.

where $f$ is the corresponding Plasma frequency (in Hertz), $n$ is the number density of the electrons (in electrons per cubic meter), $e=1.60 \times 10^{-19} \mathrm{C}$ is the electron charge, $\varepsilon_{0}=8.85 \times 10^{-12} \mathrm{Fm}^{-1}$ is the permittivity of free space, and $m=9.11 \times 10^{-31} \mathrm{~kg}$ is the electron mass.

Equation (1) shows a square-law relation between the plasma frequency, $f$, and the electron density, $n$. Points of peak electron densities are, therefore, points of peak plasma frequencies. The peak plasma frequency in ionospheric studies (also called the critical plasma frequency) is denoted $f o \mathrm{~F} 2$, after the $\mathrm{F} 2$ region of the ionosphere. In the absence of occurrences such as sporadic E (Es), the F2 region contains the maximum concentration of electrons in the ionosphere. Our map does not take into account sporadic E Layer effects. In relation to HF radio propagation, the critical plasma frequency for any location on Earth represents the highest radio frequency that the ionosphere above that location is able to reflect if the radio waves are at normal incidence. A map of $f o \mathrm{~F} 2$ values for the South African region was developed in this work, and then used to adapt the International Reference Ionosphere (IRI) model to generate electron density profiles for the region.

Published by Copernicus Publications on behalf of the European Geosciences Union. 


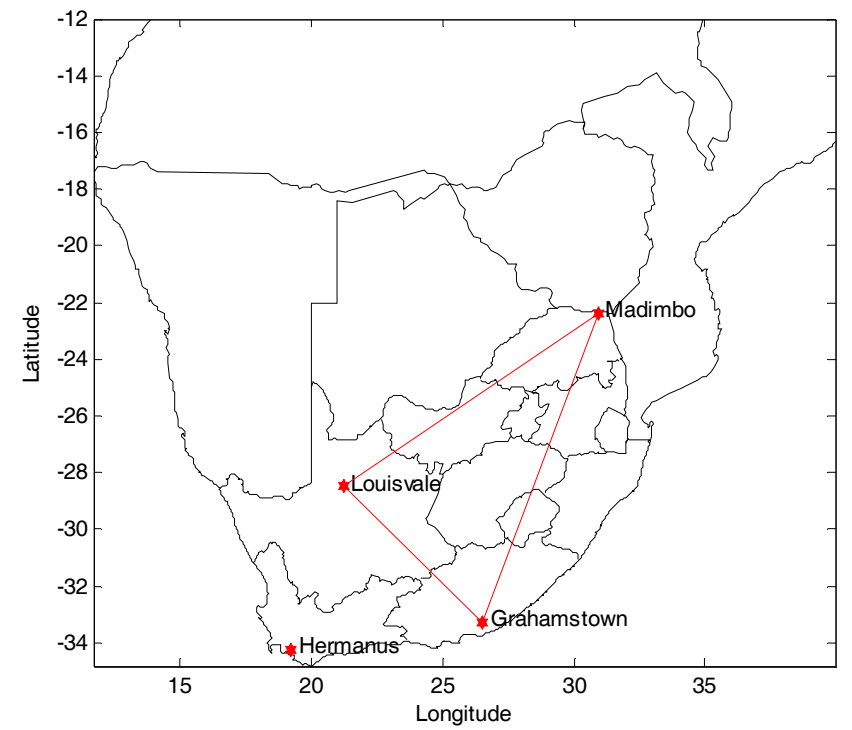

Fig. 1. Locations of the South African ionosonde stations. SABIM is used inside the marked triangular region.

\section{Available data sources}

The sources of ionospheric information used for developing the map include the IRI model, the South African Bottomside Ionospheric Model (SABIM), and measurements from ionosondes in the South African Ionosonde Network.

The IRI model is an empirical model developed using available data from all around the world. This model was considered as a data source for the map since it is the international standard for the specification of ionospheric densities and temperatures (Bilitza, 2001) and the most commonly used global model. According to Bilitza and Reinisch (2008), the IRI model has become so widely accepted that a comparison with IRI is often one of the first science tasks by an ionospheric, satellite or rocket team. The latest version of the IRI model (IRI-2007) was implemented in our map as an executable produced from the IRI FORTRAN source code so as to allow for user defined automatic operations.

SABIM is a model of South Africa's bottomside ionosphere developed using the technique of training Neural Networks (NNs) with an archive of data from 3 of the South African ionosonde stations located at Grahamstown $\left(33.3^{\circ} \mathrm{S}, 26.5^{\circ} \mathrm{E}\right)$, Madimbo $\left(22.4^{\circ} \mathrm{S}, 30.9^{\circ} \mathrm{E}\right)$ and Louisvale $\left(28.5^{\circ} \mathrm{S}, 21.2^{\circ} \mathrm{E}\right)$ as shown in Fig. 1. SABIM was utilized as an available data resource since it is a national model developed particularly for the South African region due to the insufficiencies observed in using global ionospheric models for the South African region. McKinnell and Poole (2004) noted that the IRI model was inaccurate in the South African region due to an historical paucity of available data for the region. In their words, comparisons with the IRI global model showed that, for Grahamstown, a NN-based model predicted the noon value of $f o \mathrm{~F} 2$ more realistically than the IRI. Earlier work done by McKinnell (2002) showed that SABIM predictions were more accurate than IRI predictions over Grahamstown when compared to measured data from the Grahamstown ionosonde. Section 4.5 also illustrates an improvement in performance of SABIM over the IRI at the ionosonde locations. The latest version of SABIM (version 3) was implemented as an executable produced from a code written in the $\mathrm{C}$ programming language for use in our map.

The South African Ionosonde Network currently consists of 4 ionosonde stations as shown in Fig. 1; the 3 already mentioned above and used in the development of SABIM plus the latest addition located at Hermanus (Western Cape, $34.4^{\circ} \mathrm{S}$, $19.2^{\circ} \mathrm{E}$ ). Since ionosonde measurements are the most accurate recordings of ionospheric behaviour and reflect the true state of the ionosphere at a given time and location, real-time data from the 4 ionosondes were given first priority in the development of this map.

In summary, the IRI model was incorporated into our map since it is an international standard for the ionosphere, SABIM was used since it is more adapted for the South African region, and the South African ionosonde network provides the most accurate real-time ionospheric information for the region.

\section{Developing the ionospheric map}

A major product of this work is software (written in the MATLAB programming language) that generates maps illustrating spatial and temporal representations of the South African ionosphere. The software (having a Graphical User Interface (GUI) for more user-friendliness) produces maps of the $f o \mathrm{~F} 2$ values, and the electron density profiles, over the South African region for a given set of input parameters. Figure 2 illustrates the user interface presented by the software.

To produce the $f \circ \mathrm{F} 2$ map, SABIM was used inside of the triangular region illustrated in Fig. 1. The vertices of that triangle are at the 3 ionosonde stations which were used to develop SABIM. The IRI model was used outside of the triangular region, and a smoothing function was introduced at the boundary between where these 2 models were used such that SABIM still contributed outside of the triangular region, but that its contribution decreases with increasing distance from the closest edge of the triangle. The smoothing function used is

$f=f_{\mathrm{s}} \cos ^{2} \theta+f_{\mathrm{i}} \sin ^{2} \theta$.

where $f_{\mathrm{s}}$ is SABIM's $f o \mathrm{~F} 2$ value for a location outside of the triangular region, $f_{\mathrm{i}}$ is IRI's corresponding $f o \mathrm{~F} 2$ value for that location, and $f$ is the resulting $f o \mathrm{~F} 2$ value for the location. The parameter $\theta$ is a measure of the location's distance from the closest edge of the triangle, and was arbitrarily defined to have a value of $0^{\circ}$ anywhere on the triangular edge, and linearly increases to $90^{\circ}$ at a distance of 10 longitudinal degrees $(\approx 1117 \mathrm{~km})$ from the closest triangular edge. In 


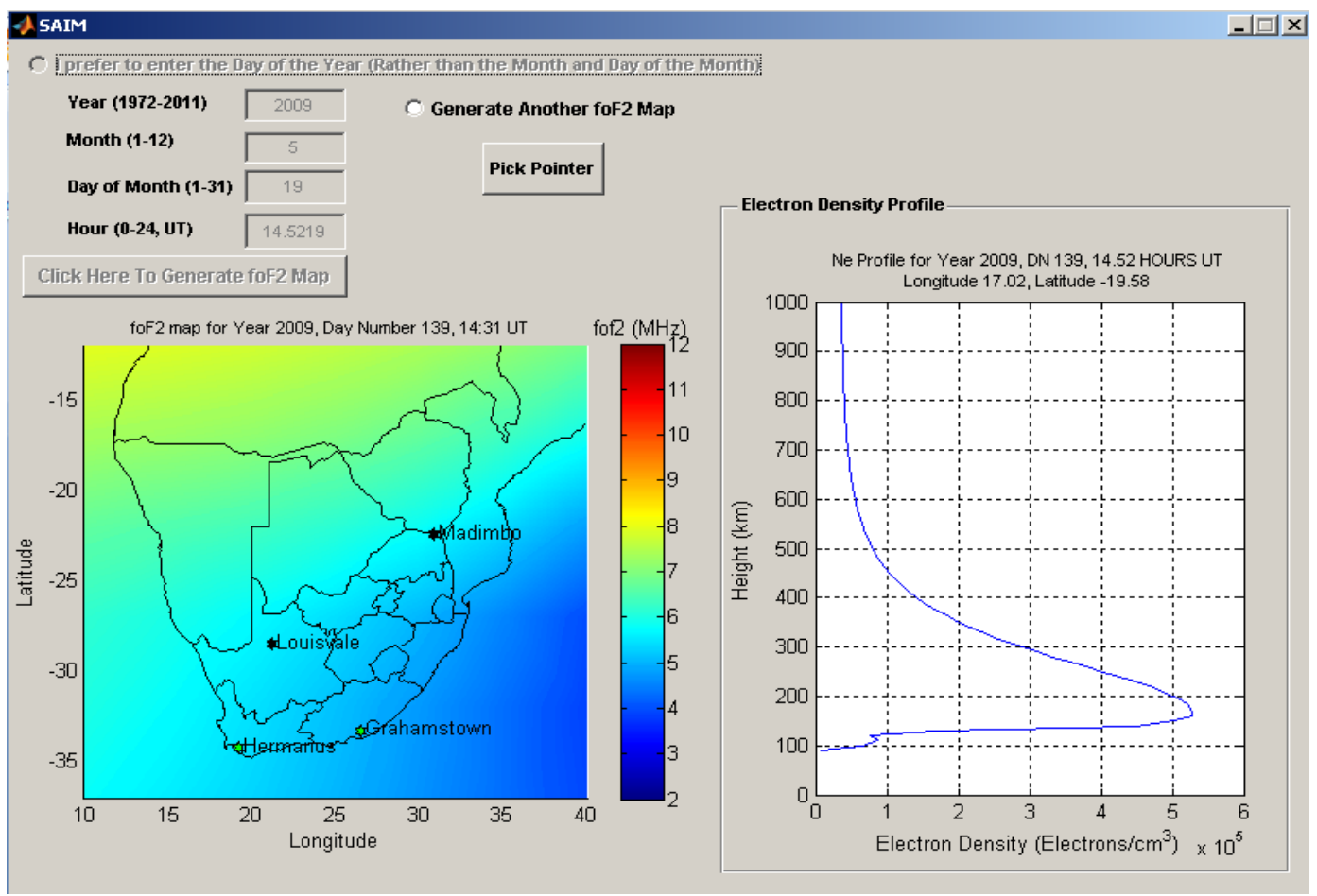

Fig. 2. The Graphical User Interface of the software developed in this work.

essence, IRI's contribution is zero for points on the triangular edge, increases with distance from the triangle, and is $100 \%$ at a distance of $1117 \mathrm{~km}$ and beyond from the closest triangular edge.

The rationale behind this combination is that SABIM is known to perform more accurately than the IRI model inside of the triangular region bounded by the 3 ionosonde stations that were used to develop the model (Poole and McKinnell, 2000), but that its performance outside of that region has not been proven.

Measurements from the ionosondes were further used to adapt the produced $f o \mathrm{~F} 2$ map to fit the ionosonde measurements; for each ionosonde location, the program calculates the difference between the measured $f o \mathrm{~F} 2$ and the $f o \mathrm{~F} 2$ value calculated by the existing modeled map at the ionosonde location, and then fits a best plane, by the method of least squares, of these differences over the whole map. This plane is added to, or subtracted from, the existing modeled map in order to adapt it to the ionosonde measurements.

To generate the electron density profile for a given location, the program uses the IRI model, but augments it with the location's $f o \mathrm{~F} 2$ and $h m \mathrm{~F} 2$ values as obtained from the map. The $h m \mathrm{~F} 2$ values are obtained by exactly the same process used for obtaining the $f o \mathrm{~F} 2$ values. SABIM also produces electron density profiles for the South African region, but was not used in the generation of electron density profiles for this work since the model, being a bottomside ionospheric model, does not produce electron density profiles for the topside ionosphere. In addition, significant time would also be required by the computer program to combine electron densities from the IRI model and SABIM at each of the altitudes involved in the construction of a single vertical density profile. Note that the electron density profiles generated by adapting the IRI model with $f o \mathrm{~F} 2$ and $h m \mathrm{~F} 2$ values from the map are contributions from all 3 sources used in the development of the map since the $f o \mathrm{~F} 2$ and $h m \mathrm{~F} 2$ values come from a combination of data from all 3 sources.

\section{Results and discussions}

\subsection{Variations over a typical day}

Figure 3a to d illustrates how the $f o \mathrm{~F} 2$ values vary over a typical day in South Africa as determined by our map. The figures show $f o \mathrm{~F} 2$ maps of the South African ionosphere for 08:00 UT (a South African morning), 12:00 UT (a South African afternoon), 16:00 UT (a South African evening), and 22:00 UT (the South African midnight) respectively for day number 13 (a summer day) of year 2009.

The maps show that the $f o \mathrm{~F} 2$ values are larger in the afternoon than for other times of the day. This is expected since in the afternoon the sun is closest to zenith. The amount of solar radiation reaching the ionosphere during this time of the day is also generally greater than during other times of the day, giving rise to greater ionospheric electron densities (and hence greater $f o \mathrm{~F} 2$ values). In the early hours of the day 


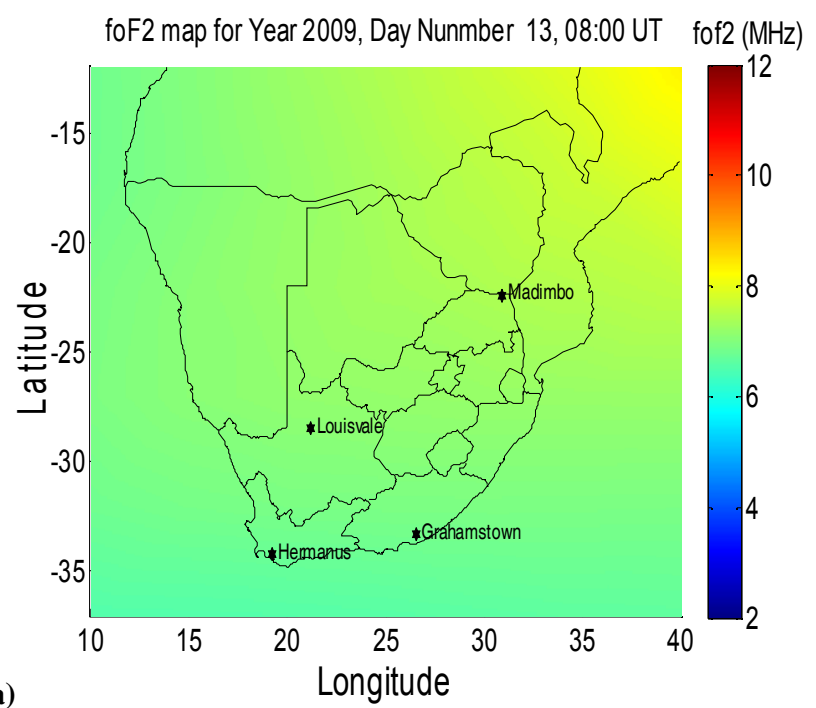

(a)

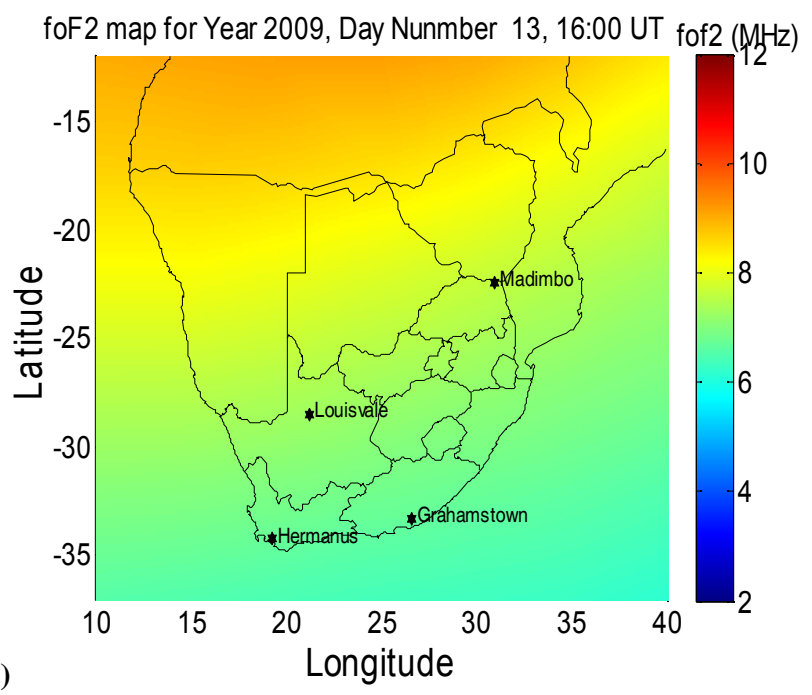

(b)
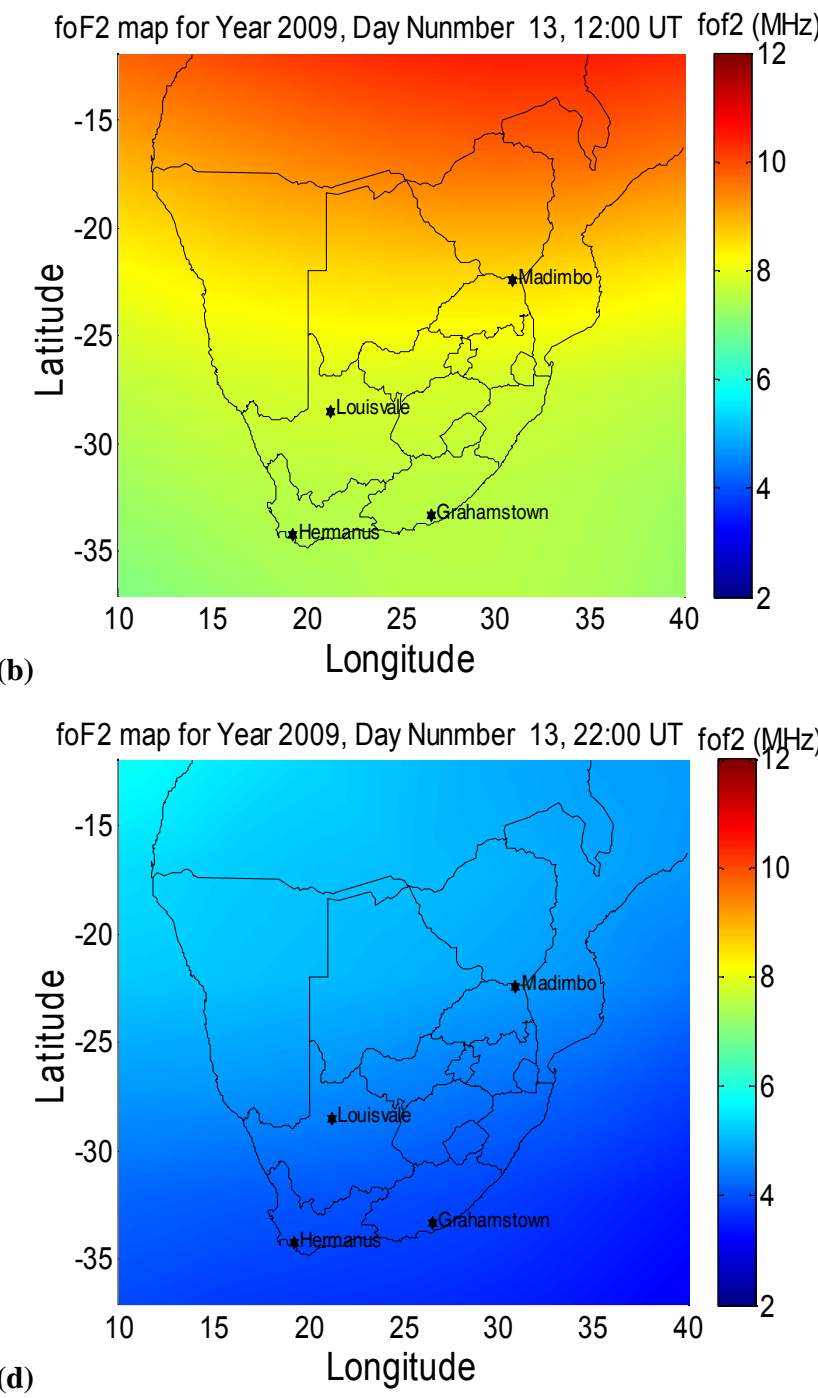

Fig. 3. Variations in $f \circ \mathrm{F} 2$ over South Africa for (a) a morning, (b) an afternoon, (c) an evening and (d) a midnight hour of a summer day in 2009.

(Fig. 3a), the sun is still rising and the $f o \mathrm{~F} 2$ values are therefore relatively lower. During the evening hours, the sun is setting and the $f o \mathrm{~F} 2$ values are therefore gradually decreasing. Nights have the lowest $f o \mathrm{~F} 2$ values due to the absence of solar radiation.

The maps also show that during the early hours of the day (Fig. 3a) the $f \circ \mathrm{F} 2$ values are greater at the north-eastern parts, during the afternoon (Fig. 3b) the region of greatest $f o \mathrm{~F} 2$ values shifts towards the north-central parts, and during the evening (Fig. 3c) the north-western parts have the greatest $f o \mathrm{~F} 2$ values, following the sun's motion from the northeast direction of the country through to the northwest direction of the country.

\subsection{Seasonal variations}

The intensity of solar radiation reaching the ionosphere changes with the seasons of a year. Figure $4 \mathrm{a}$ to $d$ illustrate variations in the South African ionosphere during the 4 seasons of year 2008. These figures are $f \circ \mathrm{F} 2$ maps for day numbers $13,104,195$, and 285 of year 2008, respectively chosen to represent a day in summer, a day in autumn, a day in winter, and a day in spring. The maps are for 10:00 UT (midday local time) for each of the chosen days.

As expected, the $f o \mathrm{~F} 2$ values are greater for the summer day than for the winter day. The tilt of the Earth's rotational axis relative to the orbital plane coupled with the Earth's revolution round the sun gives rise to seasonal modulation of the solar flux. In summer, a given hemisphere is tilted towards the sun and so experiences greater solar intensity than 


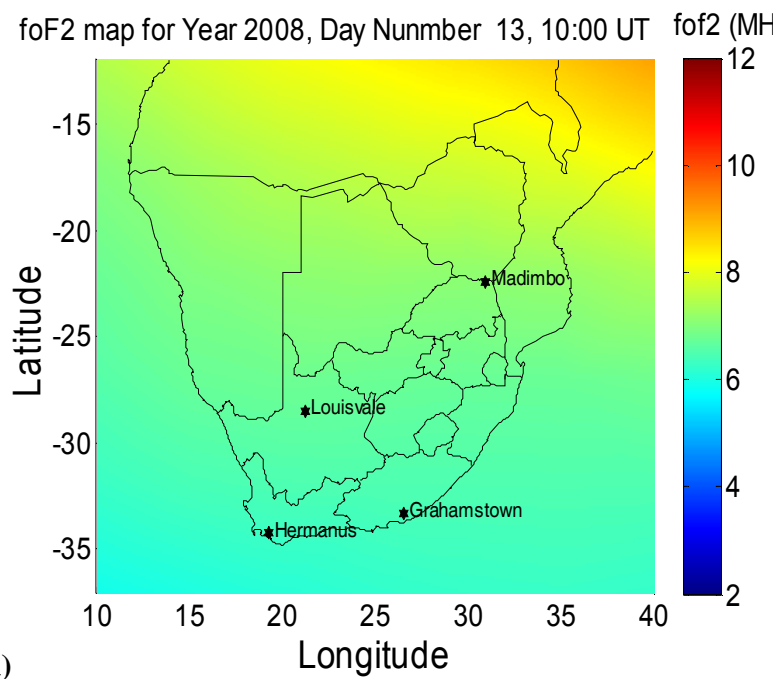

(a)

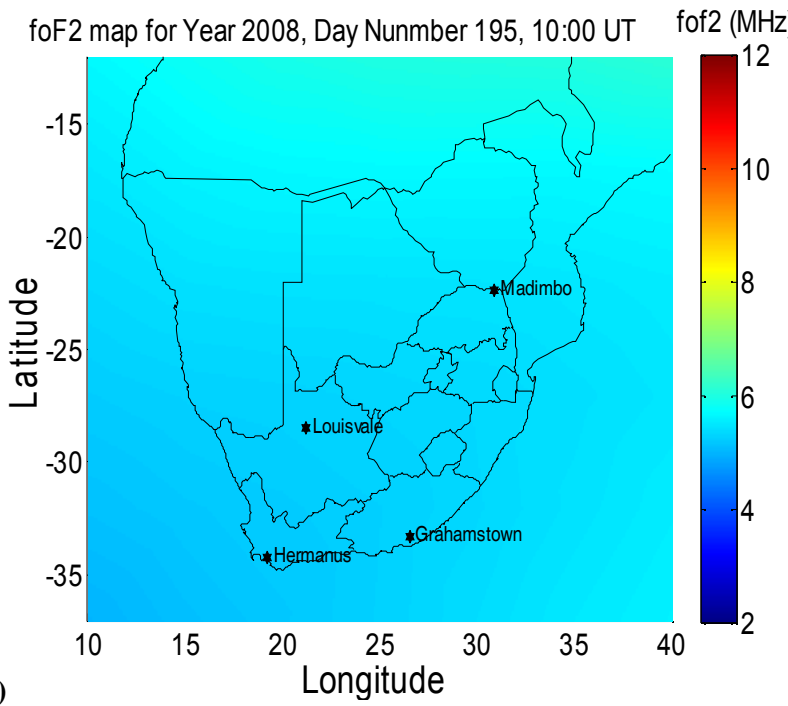

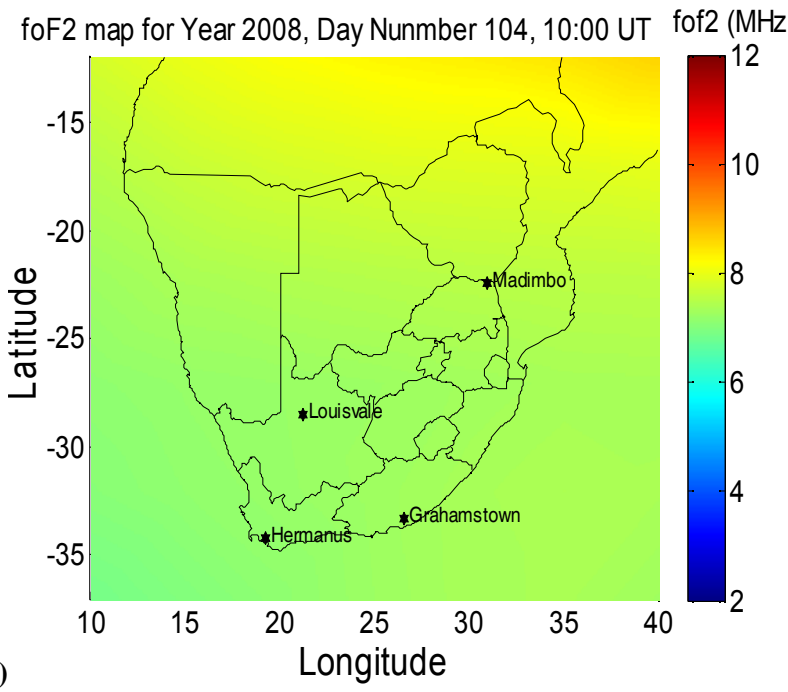

(b)

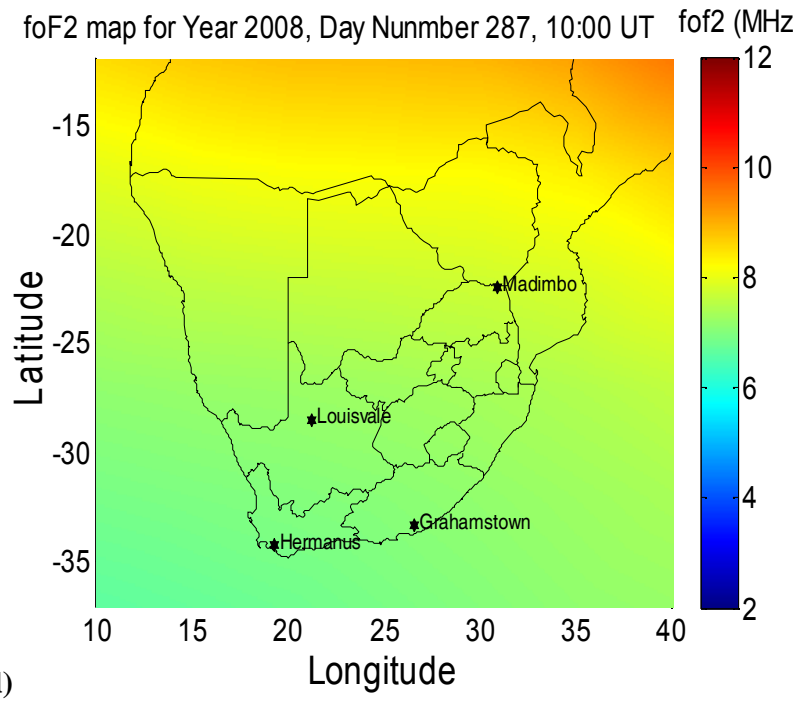

Fig. 4. Variations in $f o F 2$ over South Africa for (a) a summer day, (b) an autumn day, (c) a winter day and (d) a spring day.

in winter when the same hemisphere will be tilted away from the sun.

\subsection{Variations over a solar cycle}

The map exhibits the expected change in ionospheric response to varying degrees of solar activity. Figure 5a to c shows the foF 2 maps for identical periods of year 2000 (a year of solar maximum), year 2003 (a year of moderate solar activity), and year 2006 (a year of minimum solar activity) respectively. The maps are for 08:00 UT and day number 50 (early autumn) of each of the chosen years.

As expected, the maps show large foF 2 values for the year of maximum solar activity, moderate $f o \mathrm{~F} 2$ values for the year of moderate solar activity, and lower $f o \mathrm{~F} 2$ values for the year of minimum solar activity.

\subsection{Latitudinal and longitudinal variations}

The sun is mostly overhead at locations on, or close to, the equator, than at higher latitudes. For this reason the sun's radiation is more intense at lower latitudes than at higher latitudes. The overall effect is a gradual degradation in ionospheric photo-ionization, and hence foF 2 values, as we move from the equatorial regions to the polar regions. This degradation is evident in each of the foF 2 maps illustrated. Longitudinal variations are related to local-time variations; for a given locality, the intensity of solar radiation increases as the sun rises, peaks at about local midday, and decreases as the sun sets.

Movies produced using these maps (available from the first author) more clearly demonstrate the group of variations described above. The movies show, graphically and 


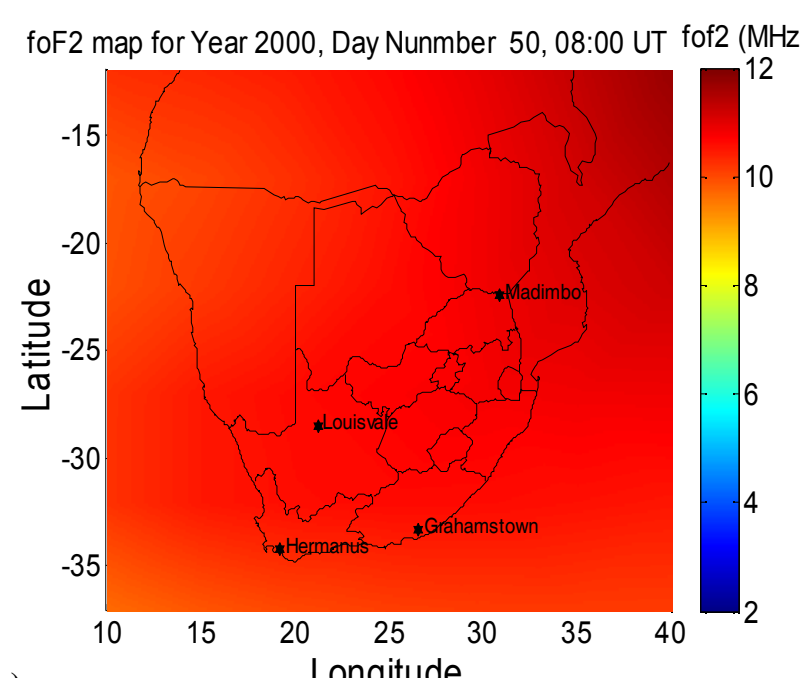

(a)

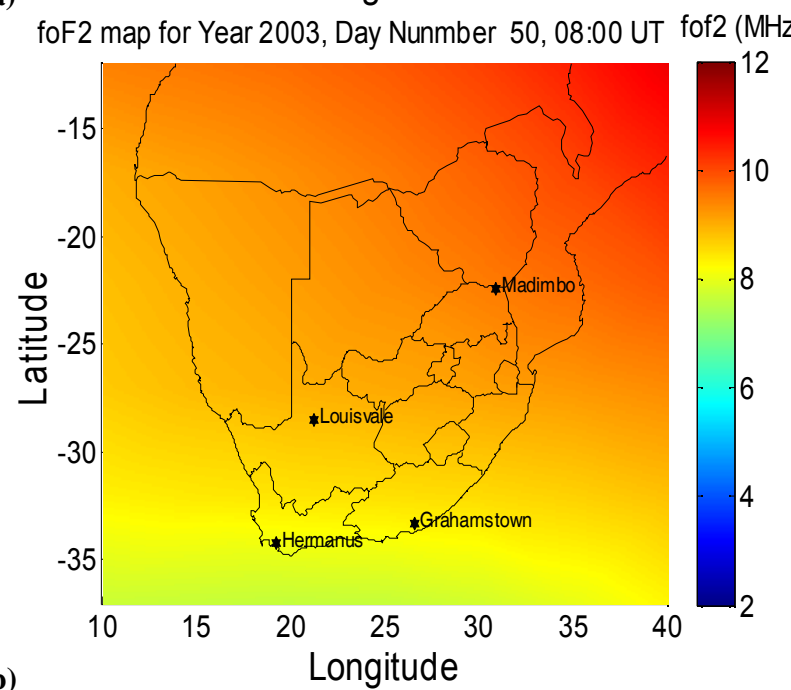

(b)

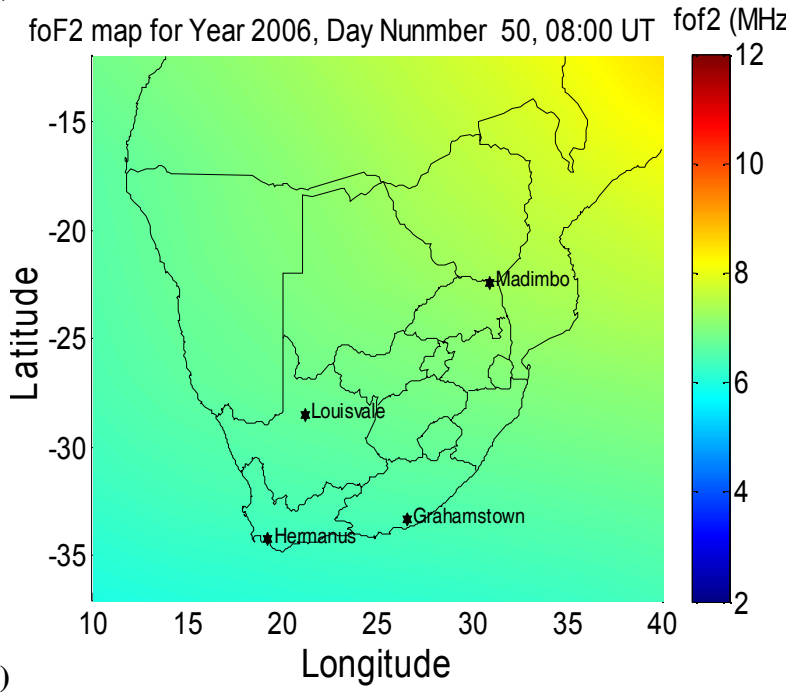

Fig. 5. Variations in $f o \mathrm{~F} 2$ over South Africa for (a) a year of maximum solar activity, (b) a year of moderate solar activity and (c) a year of minimum solar activity. dynamically, the spatial and temporal variations in the foF2 values over the South African region.

\subsection{Performance of the map at storm times}

A comparison is made here between the MAP- $f \circ \mathrm{F} 2$ values, the IRI-foF 2 values, and the ionosonde $f o \mathrm{~F} 2$ values from the 3 ionosonde stations (Grahamstown, Louisvale, and Madimbo) at storm times. The storm periods considered were taken from times of year 2000 to year 2006 when the geomagnetic storm-time index, Dst, was less than $-100 \mathrm{nT}$, and when ionosonde data was available. Table 2 illustrates the average of the absolute percentage deviations of the Map$f o \mathrm{~F} 2$ values and the IRI- $f o \mathrm{~F} 2$ values from the ionosonde- $f \circ \mathrm{F} 2$ values, calculated using the formula given in Eq. (3).

Average of absolute percentage deviations

$$
=\frac{\sum_{i=1}^{n}\left(100 \times\left|\frac{x_{\mathrm{i}}-\bar{x}_{\mathrm{i}}}{x_{\mathrm{i}}}\right|\right)}{n}
$$

Where the $x_{\mathrm{i}} \mathrm{s}$ represent the ionosonde-foF 2 values, the $\bar{x}_{\mathrm{i}} \mathrm{s}$ represent the MAP-foF2 values or the IRI- $f \circ \mathrm{F} 2$ values as the case may be, and $n$ represents the sample size.

The Map- $f o F 2$ values used here are without incorporating the ionosonde data into the map. Incorporating the ionosonde data would mean a zero deviation of the Map-foF2 from the ionosonde foF2.

To graphically present the results of the comparison, a subset of storm times were selected from the periods when Dst was less than $-100 \mathrm{nT}$, such that the periods under consideration were representative of all seasons of a year, and all times of a day. The results are illustrated in Fig. $7 \mathrm{a}-\mathrm{c}$ and reveal that both models provide good estimates of $f_{o} \mathrm{~F} 2$ during storm times, with Map-foF2 being slightly closer to the observations than IRI- $f \circ \mathrm{F} 2$ where the two models deviated significantly. In general, the overall improved performance of Map-foF2 over IRI- $f o F 2$ is in line with the idea that the IRI model performs better when adapted with regional data. Earlier work by McKinnell (2002) also showed that SABIM performed better than IRI over Grahamstown when compared to data recorded with the Grahamstown digisonde.

The storm times in Fig. $7 \mathrm{a}-\mathrm{c}$ are shown in the format "YYYY-DDD-HH" where YYYY is year, DDD is day of the year, and $\mathrm{HH}$ is hour of the day. Dst indices were obtained from the website of the World Data Centre for Geomagnetism (http://wdc.kugi.kyoto-u.ac.jp/dstdir/).

\section{Comparison with GPS-derived TEC}

This section illustrates a comparison between vertical Total Electron Content (TEC) values derived from Global Positioning System (GPS) receivers and vertical TEC values obtained as follows: 


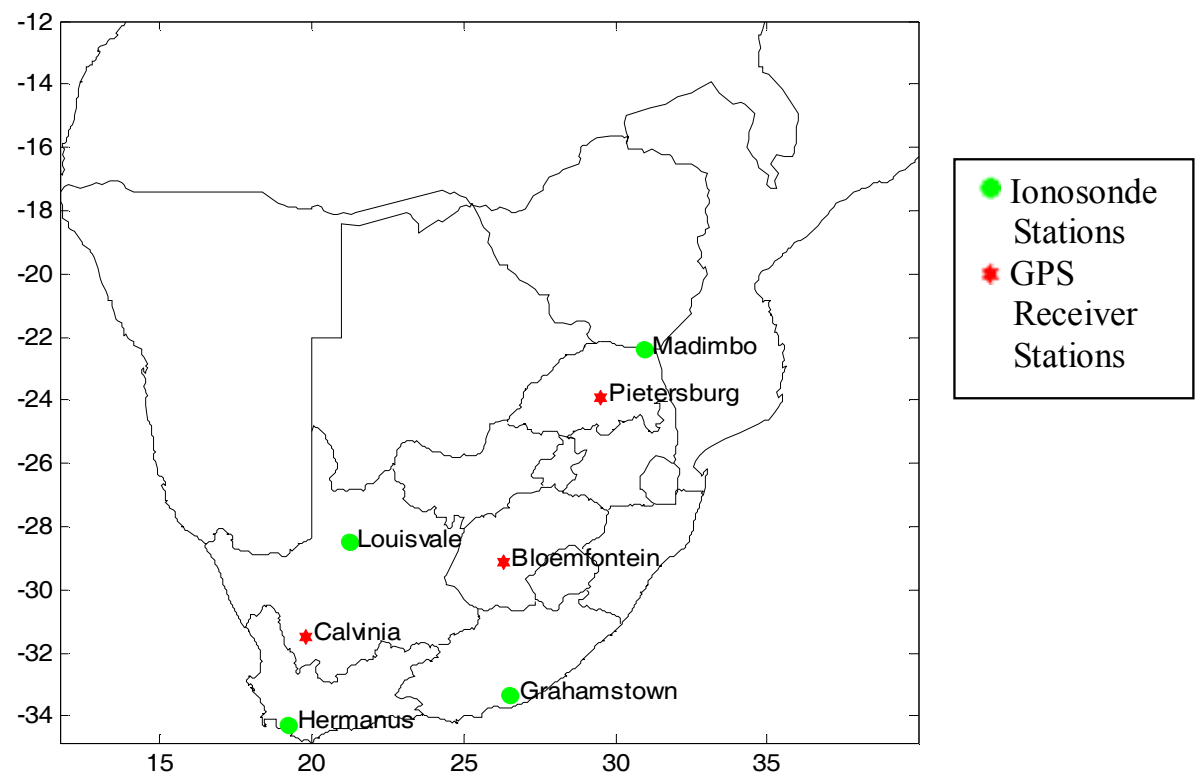

Fig. 6. Location of the ionosonde stations and the GPS receiver stations used for the validation of the TEC values obtained from the map.

Table 1. Correlation coefficients between GPS-TEC values, IRI-TEC values and MAP-TEC values.

\begin{tabular}{lccc}
\hline Station & $\begin{array}{c}\text { Correlation coefficient between } \\
\text { GPS-TEC and IRI-TEC }\end{array}$ & $\begin{array}{c}\text { Correlation coefficient between } \\
\text { GPS-TEC and MAP-TEC }\end{array}$ & Sample size \\
\hline Bloemfontein & 0.69 & 0.83 & 201 \\
Calvinia & 0.73 & 0.85 & 189 \\
Pietersburg & 0.72 & 0.83 & 135 \\
\hline
\end{tabular}

1. Vertical TEC values were derived from the map using the IRI model; the IRI model was adapted with $f_{o F} 2$ and $h m \mathrm{~F} 2$ values from the map so as to output the TEC values. For simplicity and quick identification, TEC values derived using this method will be referred to as MAPTEC.

2. Vertical TEC values were also obtained from the IRI model using the standard IRI options. For simplicity and quick identification, TEC values derived using this method will be referred to as IRI-TEC.

Vertical TEC values were also derived from GPS data using the method described by Opperman et al. (2007). This will be referred to as GPS-TEC.

To obtain the MAP-TEC and the IRI-TEC, the upper integration limit of the IRI model was set to $20200 \mathrm{~km}$ (the altitude of the GPS satellites), and the NeQuick option of the IRI was used for the topside of the ionosphere.

GPS data from the following three dual-frequency GPS receiver stations within South Africa were used. The stations were chosen to cover certain regions of interest and are indicated in Fig. 6.
1. The Bloemfontein station $\left(26.3^{\circ} \mathrm{E}, 29.1^{\circ} \mathrm{S}\right)$ was chosen to be representative of places inside the quadrilateral region bounded by the 4 ionosonde stations in the South African ionosonde network. Bloemfontein is in the central part of the country.

2. The Calvinia station $\left(19.8^{\circ} \mathrm{E}, 31.5^{\circ} \mathrm{S}\right)$ was chosen to be representative of places outside the quadrilateral region bounded by the 4 ionosonde stations in the South African ionosonde network. Calvinia lies in the southwestern part of the country.

3. The Pietersburg station $\left(29.5^{\circ} \mathrm{E}, 23.9^{\circ} \mathrm{S}\right)$ was chosen to be representative of places close to the ionosonde stations. Pietersburg is close to Madimbo, in the northeastern part of the country.

Available GPS-TEC values for 10:00 UT of each day were used. IRI-TEC values and MAP-TEC values corresponding to these times were obtained. Figure 8a to c illustrates how the IRI-TEC and MAP-TEC values compare with the GPSTEC values at the three selected GPS receiver stations. We note here that since the GPS-TEC values are measured values, they show much more day-to-day variability than either 
Table 2. Deviation of the MAP- $f o F 2$ values and the IRI- $f o F 2$ values from ionosonde- $f o F 2$ values, as calculated from Eq. (3).

\begin{tabular}{lccc}
\hline Station & $\begin{array}{c}\text { Average of the absolute percentage } \\
\text { deviations of the MAP- } f \circ \mathrm{F} 2 \\
\text { values from the ionosonde } f \circ \mathrm{F} 2 \text { values }(\%)\end{array}$ & $\begin{array}{c}\text { Average of the absolute percentage } \\
\text { deviations of the IRI- } f \circ \mathrm{F} 2 \text { values } \\
\text { from the ionosonde } f o \mathrm{~F} 2 \text { values }(\%)\end{array}$ & $\begin{array}{c}\text { Sample size } \\
\text { Grahamstown }\end{array}$ \\
$\begin{array}{l}\text { Louisvale } \\
\text { Madimbo }\end{array}$ & 18.14 & 22.24 & 488 \\
\hline
\end{tabular}
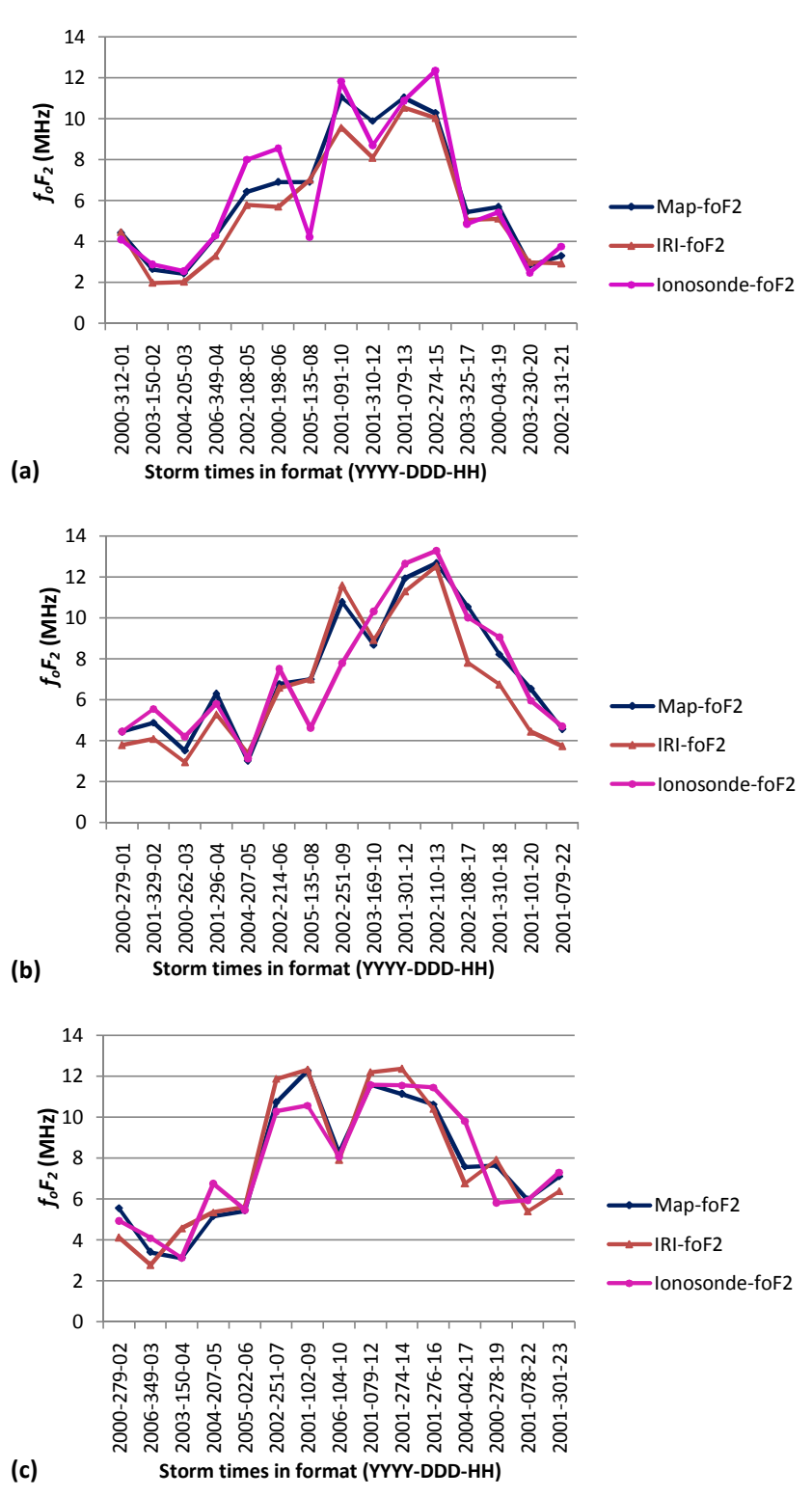

Fig. 7. Comparison of storm time $f o \mathrm{~F} 2$ values for (a) Grahamstown, (b) Louisvale and (c) Madimbo.

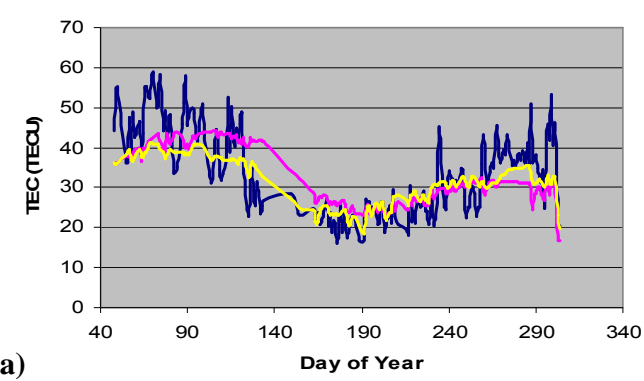

(a)
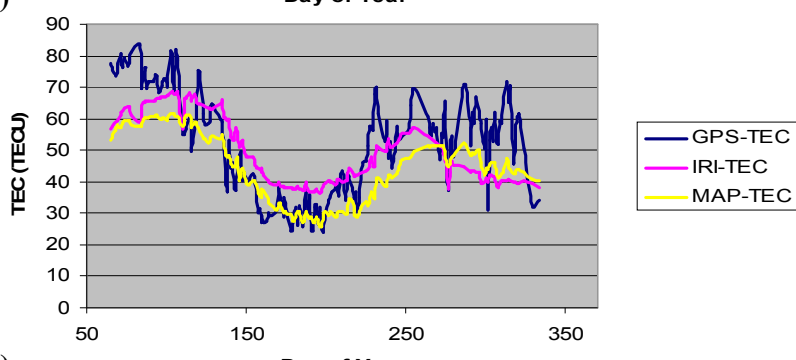

(b)
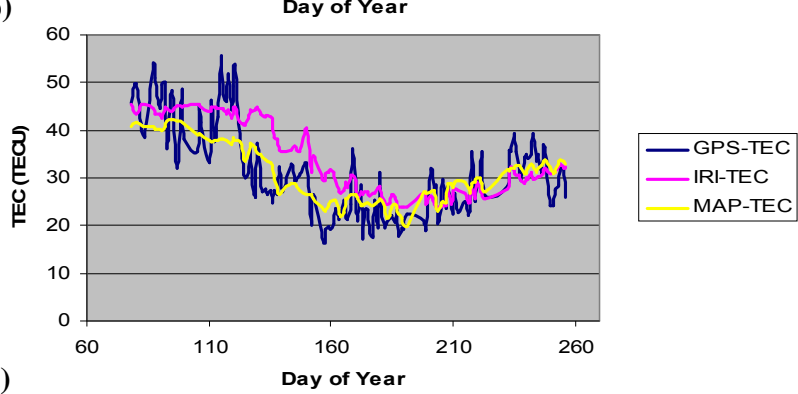

Fig. 8. Comparison of the 10:00 UT TEC values for (a) year 2003 at Bloemfontein, (b) year 2002 at Calvinia and (c) year 2003 at Pietersburg.

of the modeled values, and as such we do not expect a perfect systematic relation between them. Table 1 shows the corresponding correlation coefficients. Generally, both the IRITEC and the MAP-TEC correlate well with the GPS-TEC values, but the results show a better correlation between the MAP-TEC and the GPS-TEC than the correlation between the IRI-TEC and the GPS-TEC. This validates the improvement obtained by using our $f o F 2$ map to adapt the IRI model for the South African region. 


\section{Conclusion}

Most industries that make use of Earth-Space systems require ionospheric maps to adequately correct for the effects of the ionosphere on their systems. This paper presented the development of an ionospheric map that can be used for this purpose.

A major limitation of the map is that it is spatially constrained to the South African region, a great concern for users who will be interested in using the map beyond these boundaries. The techniques presented here can be applied to any region with an adequate number of ionosondes. The possibility of expanding the map to include other African countries is proposed for future work. A major deterrent to achieving this is the paucity of ionospheric information available for the African continent, especially from ionosondes. However, given the increased availability of GPS receivers, GPS data may be used in conjunction with the available models. It is hoped that the map will subsequently be developed to suit the needs of various users. It is also planned that this map, and subsequently a map covering Africa, will become a regular real-time feature of the African Space Weather Regional Warning Centre website (http://spaceweather.hmo.ac. za). Since the accuracy of the map greatly depends on that of the models used, and since both models are regularly updated, the plan is to regularly update the map in line with the models so as to maintain desirable accuracies.
Acknowledgements. Special thanks to the National Astrophysics and Space Science Programme (NASSP) for their financial support. We appreciate the IRI team for making the IRI model available, and Ben Opperman for helping with the GPS-derived TEC data.

Topical Editor M. Pinnock thanks D. Bilitza and A. Belehaki for their help in evaluating this paper.

\section{References}

Bilitza, D.: International Reference Ionosphere 2000, Radio Sci., 36, 261-275, 2001.

Bilitza, D. and Reinisch, B. W.: International Reference Ionosphere 2007: Improvements and new parameters, Adv. Space Res., 42, 599-609, 2008.

Chen, F. F.: Introduction to plasma physics and controlled fusion, Springer, 1984.

McKinnell, L. A.: A neural network based ionospheric model for the bottomside electron density profile over Grahamstown, South Africa, PhD Thesis, Rhodes University, 2002.

McKinnell, L. A. and Poole, A. W. V.: Neural network-based ionospheric modelling over the South African region, South African Journal of Science, 100, 519-523, 2004.

Opperman, B. D. L., Cilliers, P. J., McKinnell, L. A., and Haggard, R.: Development of a regional GPS-based ionospheric TEC model for South Africa, Adv. Space Res., 39, 808-815, 2007.

Poole, A. W. V. and McKinnell, L. A.: On the predictability of foF2 using neural networks, Radio Sci., 35, 225-234, 2000.

World Data Centre for Geomagnetism: Geomagnetic Dst Index Home Page, http://wdc.kugi.kyoto-u.ac.jp/dstdir/, 2009. 